\title{
(6) Leadership development and primary care
}

\section{OPEN ACCESS}

${ }^{1}$ NHS Leadership Academy,

Leeds, UK

${ }^{2}$ Faculty of Medical Leadership and Management, London, UK ${ }^{3}$ Improvement Directorate, NHS England and NHS Improvement, Leeds, UK

\section{Correspondence to}

Dr Tim Swanwick, NHS

Leadership Academy, Leeds LS1

4BJ, UK;

tim.swanwick@

leadershipacademy.nhs.uk

Received 6 March 2019 Revised 30 March 2019 Accepted 15 April 2019 Published Online First 2 May 2019

Check for updates

(C) Author(s) (or their employer(s)) 2019. Re-use permitted under CC BY-NC. No commercial re-use. See rights and permissions. Published by BMJ.

To cite: Swanwick T, Varnam R. BMJ Leader 2019:3:59-61.

Tim Swanwick, ${ }^{\oplus 1,2}$ Robert Varnam ${ }^{3}$

Health services across the developed world are evolving rapidly, and over the coming years some of the most wide-ranging changes are expected to occur in primary care. Primary care includes the largest number of providers, and in the UK accounts for the largest proportion of patient contacts with the National Health Service (NHS), around 300 million per year in general practice alone. ${ }^{1}$ To meet the needs of a changing population, adopt vital innovations, redesign for greater sustainability, and support increasing personalised and integrated care, primary care teams will need to evolve the way they work. In addition, there is growing evidence that community-building-working with and growing local community 'assets'-in partnership with local authorities and the voluntary sector is essential to achieving better population health outcomes, improved self-management of long-term conditions and in reducing demand. ${ }^{2}$ Achieving these transformational changes represents a leadership challenge of unprecedented scale and complexity and requires that primary care professionals are inspired, equipped and supported in leadership roles.

The need for an improved leadership development offer for primary care has been recognised in successive national policy documents, including in England the General Practice Forward View, ${ }^{3}$ Developing People - Improving Care ${ }^{4}$ and a new Long Term Plan for the NHS. ${ }^{5}$ But this is a complex landscape and there are multiple agencies and stakeholders involved. No one organisation holds the complete picture, and so an engaged and collaborative effort, aligned to an agreed strategic approach, is essential for progress to be made.

\section{THE LEADERSHIP CHALLENGE IN PRIMARY CARE}

The unique configuration and challenges of primary care point to the need for some specific approaches to leadership development, distinct from many other sectors of the health service. (For the remainder of this paper we refer throughout to primary care in England and view primary care broadly as a citizen's first point of contact with the healthcare system providing comprehensive, continuous and coordinated care with a workforce including, among others, general practitioners, nurses, practice staff, pharmacists, opticians and dentists.)

First, the scale and depth of change required in primary care over the coming years are arguably greater than anywhere else in the NHS, with significant future implications for the capacity and capability required for leadership. Sustaining high-quality services day-to-day is also reliant on excellent leadership and management, made more challenging by the profound service, recruitment and retention pressures in primary care. Change is already under way throughout much of England (as in other developed countries), but there is still much to be done. Providers will need to continue introducing new clinical models, design new patient pathways, introduce a broader workforce, make greater use of technology, build patients' ability to self-care and work in much closer collaboration with other teams and organisations. While the core values of primary care are expected to remain unchanged, providers are actively innovating in almost every aspect of how care is delivered.

Second, primary care leadership is expected to work increasingly across its internal boundaries, as networks of practices and associated neighbourhood teams, share resources and collaborate to improve care and provide innovative services for patients and their populations. Collaboration between practices is not a new phenomenon. However, the changes envisaged in the NHS Long Term Plan will involve a step change in the degree of collaboration between organisations, including with other types of providers in the health and care system. Leading changes in systems, processes and patterns of behaviour for large numbers of staff and colleagues who do not work for you is a new challenge for most healthcare leaders but will need to become the norm in primary care.

Third, in addition to leadership of primary careleadership of teams, organisations and networks providing primary care-leadership from primary care is pivotal to the future development of health and care systems more widely. It is expected that new primary care networks will play a greater role in the leadership of integrated care systems. Strategic system leadership here then is required at various levels, often simultaneously, requiring the juggling of peer, team, organisation, sector, community and system leadership to be effective. This results in a complex range of development needs to be met.

Finally, a number of 'on-the-ground' contextual factors mark primary care out as having distinct needs, namely the following:

- There has historically been less investment in building leadership and management skills in primary care than in other parts of the health service. As a result, the majority of clinical leaders have received little or no formal leadership development, and there is a deficit of basic managerial skills in a significant minority of practices. ${ }^{6}$

- Organisational structures and contractual relationships differ significantly from those in secondary care, and learning development and support infrastructure is harder to identify 
(although, in England, a commitment to multiprofessional training hubs and a support offer to primary care networks offer some encouragement in this regard).

- There is a lack of clear opportunities for managerial and/or hierarchical progression, supported by the employer or the system.

- Leadership discourses can be considered 'alien' and leadership as practice is often undervalued in comparison with other parts of the healthcare system.

- NHS appraisals for clinicians in primary care do not always place the same emphasis on leadership development as in other settings.

- General practitioners continue to predominate in a rapidly diversifying workforce for whom opportunities for wider leadership roles may not be readily available.

- An increasingly salaried service has resulted in the loss of some on-the-job leadership and management learning for a growing proportion of doctors.

- A range of personal and professional commitments tend to result in a preference for localism and a reluctance to 'travel' far from the immediate service environment.

- Funding to support continuing professional development and 'backfill' is hard to find and is not as embedded in organisational budgets or cultures to anything like the same extent as in secondary care.

- Staff have limited ability to take time out of day-to-day duties in order to engage in leadership development.

- Academic programmes have limited appeal to primary care staff, and generic programmes, aiming to prepare NHS staff for positional leadership roles, are often less relevant to the context of primary care.

\section{WHAT KIND OF LEADERSHIP?}

The overarching purpose of any approach to primary care leadership development is to improve the health and wellbeing of populations, including supporting a shift from reactive approaches to illness by individual practitioners, to the building of healthy communities led across systems of health and social care.

The focus of such development must therefore shift from individualistic hierarchical leaders, working primarily within and for a single team, to collective leadership that creates compassionate and inclusive cultures, inspires commitment to create healthy communities, mobilises large-scale change across a geographical area, and engages local people and service users. A new understanding is required of how leadership is exercised and what it means to be a leader. This will involve paying attention to collective identity and shared purpose, and different approaches towards power and change.

There is a need to shift the focus from the leadership of teams and organisations to leading across networks and systems. New models of joined-up care will require a step change in collaboration across boundaries and sectors and a stronger role for primary care providers in leading the local health and care system.

And there is a need to shift the focus from managing today's business to designing future services and leading change. Alongside the responsibility to run safe and effective services, primary care leaders need to lead significant programmes of service redesign and ensure a vision of improved ways of working is realised.

This expansion of the concept of primary care leadership is likely to be required internationally, not only within the UK. All developed nations are facing demographic pressures from ageing populations and increasing multimorbidity, and a consequent rise in demand for a new generalism that can provide innovative approaches to both person-centred and population-focused care. Without the kind of primary care transformation described above, and already being pioneered by some, it is unlikely that any developed nation can expect to meet patient needs and deliver affordable healthcare. And it is welcome that a growing number of countries are recognising the need to build the capacity and capability for leadership in primary care.

\section{WHAT KIND OF LEADERSHIP DEVELOPMENT?}

To support these vital shifts, primary care leaders need access to a menu of development. The following elements are important for this:

- A range of different methodologies, including courses, programmes, eLearning, action learning, coaching and peer support.

- The utilisation of a variety of different platforms, including both virtual and face-to-face experiences, and there should be opportunities to attend events which are local as well as ones which connect attendees to colleagues from across the country.

- Coverage of the full gamut of responsibilities and ways of working for primary care leaders, including team and organisational leadership, continuous quality improvement, design of new and improved services, finance, system leadership and governance, strategic planning, community development and the use of the so-called 'new power" ${ }^{7}$ approaches to change.

- Offers that are accessible to and credible with primary care leaders from different disciplines, reflecting the growing diversity of the primary care workforce and the strengths of multidisciplinary working.

- Offers that are able to satisfy the needs of professionals with widely differing levels of experience, recognising the lack of formal career progression patterns in this sector.

- Opportunities for new and emerging leaders to access relevant development and support. This will need to be part of a new focus on talent management in primary care management and leadership.

In common with all leadership development, such provision should include more than just academic learning or training. Development programmes should help leaders grow knowledge, skills, perspectives, confidence and resilience. They will need to include 'learn-while-doing' approaches, combine learning from evidence, personal experience, local communities and peers, and include a focus on the leader as a person not just a role. There should be opportunities to learn from colleagues throughout the NHS as well as from social care, the wider public sector and from a variety of other organisational contexts. Importantly, they should also provide development that is 'horizontal'supporting the acquisition of wider ranges of knowledge, skills and behaviours - and 'vertical'- a longitudinal process in which participants' evolving sense of an uncertain and ambiguous world becomes increasingly more complex, systemic and inclusive. ${ }^{8}$

\section{CONCLUSION}

If we are successful in responding to the needs outlined and address development in the manner described, we envisage a future where leadership and management is welcomed and embraced by the primary care community as an essential part of their professional responsibilities. Greater engagement will lead to a heightened sense of control and meaning in work, and 
ultimately improved outcomes for patients and populations. This will require an integrated system of leadership and management development that is readily available and accessible, engaging all stakeholders across the primary care landscape and within each primary care delivery organisation. All of which will require stable long-term funding of a magnitude that recognises the scale of the challenge and the historic underinvestment in primary care leadership. The prize on offer? That primary care will take its place in leading the profound system changes required in health and care to respond to the future needs of patients, local communities and wider populations.

Acknowledgements This paper draws, with permission, from a series of discussions and workshops held over the course of 2018 by a National Primary Care Leadership Development Group, including representation from British Medical Association, Coalition for Collaborative Care, Faculty of Medical Leadership and Management, Family Doctors Association, Health Education England, National Association of Patient Participation, National Association of Primary Care, New NHS Alliance, NHS Clinical Commissioners, NHS Collaborate, NHS England, NHS Improvement, NHS Leadership Academy, Practice Management Network, Allied Health Professions Federation, Royal College of General Practitioners, Royal College of Nursing and Royal Pharmaceutical Society.

Contributors TS and RV planned and wrote the article which draws, with permission, from a series of discussions and workshops held over the course of 2018 by a National Primary Care Leadership Development Group. TS submitted the article and led the response to feedback.

Funding The authors have not declared a specific grant for this research from any funding agency in the public, commercial or not-for-profit sectors.
Competing interests TS is the national lead for primary care within the NHS Leadership Academy.

Patient consent for publication Not required.

Provenance and peer review Not commissioned; externally peer reviewed.

Open access This is an open access article distributed in accordance with the Creative Commons Attribution Non Commercial (CC BY-NC 4.0) license, which permits others to distribute, remix, adapt, build upon this work non-commercially, and license their derivative works on different terms, provided the original work is properly cited, appropriate credit is given, any changes made indicated, and the use is non-commercial. See: http://creativecommons.org/licenses/by-nc/4.0/.

\section{REFERENCES}

1 Watson N. GP partnership review: final report, 2019. Available: www.gov.uk/ government/publications/gp-partnership-review-final-report [Accessed, 17 Jan 2019].

2 NESTA and The Health Foundation. At the heart of health realising the value of people and communities, 2016. Available: https://media.nesta.org.uk/documents/at_the_ heart_of_health_-_realising_the_value_of_people_and_communities.pdf [Accessed 28 Mar 2019].

3 NHS England. General practice forward view, 2016. Available: www.england.nhs.uk/ gp/gpfv/ [Accessed 17 Jan 2019].

4 NHS Improvement. Developing people - improving care, 2016. Available: https:// improvement.nhs.uk/resources/developing-people-improving-care/ [Accessed 17 Jan 2019].

5 NHS England. NHS long term plan, 2019. Available: www.england.nhs.uk/long-termplan/ [Accessed 17 Jan 2019].

6 Care Quality Commission. The state of care in general practice 2014 to 2017, 2018. Available: https://www.cqc.org.uk/publications/major-report/state-care-generalpractice-2014-2017 [Accessed 28 Mar 2019].

7 Timms H, Heimans J, Power N. How power works in our hyperconnected world-and how to make it work for you. London: Macmillan, 2018.

8 Petrie N. Future trends in leadership development. centre for creative leadership, 2014, 2014. Available: http://insights.ccl.org/articles/white-papers/future-trends-in-leadershipdevelopment-2/ [Accessed 17 Jan 2019]. 